\title{
International linking of research and development on the model of Laser Centre Hanover
}

\section{Klaus-Dieter Nowitzki, Olaf Boedecker}

Klaus-Dieter Nowitzki, Olaf Boedecker, "International linking of research and development on the model of Laser Centre Hanover," Proc. SPIE 9664, Ninth International Topical Meeting on Education and Training in Optics and Photonics, 96640E (24 October 2005); doi: 10.1117/12.2207789

SPIE Event: Ninth International Topical Meeting on Education and Training in Optics and Photonics, 2005, Marseille, France 
This paper is freely available as a resource for the optics and photonics education community.

\title{
Ref ETOP104
}

\section{International linking of research and development on the model of Laser Centre Hanover}

\author{
Klaus-Dieter Nowitzki, Olaf Boedecker
}

Laser Zentrum Hannover e.V., Hollerithallee 830419 Hannover, Germany

\begin{abstract}
Asia is becoming one of the most important regions in the world from the political, economic and scientific point of view. Germany believes that it is becoming increasingly necessary to cooperate with certain Asian countries especially for scientific and technological reasons. Above and beyond exchanges of scientists, the scientific and technological cooperation will be organized to cover projects with specific targets and to find solutions to important problems.

International economic development is characterized by a mixture of competition and cooperation within the context of growing globalization. Germany, being one of the world's largest exporting nation, must therefore combine its active role in cooperation with these countries in the fields of education, research and innovation with economic cooperation. The Laser Centre Hanover pursues the goal of establishing and operating a Chinese German center for training and further education in laser technology and setting up a joint platform for long-term German Chinese cooperation in laser technology. An optimized traininginfrastructure combined with modern production processes support consequently long-term German businesses in China and secures their market-shares. LZH establishes Laser academies for skilled workers and technical decision makers in Shanghai and Changchun together with local universities and German partners.

Due to the economic growth, Russia records since more than two years, the economic conditions are improving the cooperation between Germany and Russia step-by-step. The main goal of Russian science-politics is to stabilize an efficient scientific-technical potential with better chances in the global competition. The German-Russian scientific and technological cooperation plays an important role in this context. It has considerablyincreased in the last years in terms of width and depth and virtually includes all areas of science and technology at present. The region around Moscow is regarded as the by far strongest economic region in Russia. The LZH establishes a testing-, education and consulting-center for laser technology, to support Russian SMEs regarding the use of modern laser technology in production. The technology- und innovation transfer process for German laser manufacturers and research institutes in Russia is completed by the establishment of a German-Russian network for optical technologies.

Both projects are sponsored by the German Federal Ministry of Education and Research.
\end{abstract}

\section{Key words}

Lasertechnology; Lasermaterialprocessing; Training and further education; Testing and consulting; Training of skilled workers and laser operator; China; Russia; Sino German Laser Academy, Moscow Laser Innovation Center; Laser Zentrum Hannover; Changchun; Shanghai, Changchun University of Science and Technology; Tongji University; Moscow Laser Association

\section{Summary}

Today's globalization affects every sector in industry and research. The dynamics and complexity especially in high technology industries moves the request to use this globalization trend for improving scientific and technological efficiency to the foreground. 
The Laser Centre Hannover (LZH) is presently involved in two international cooperation projects. In China the LZH is establishing a Sino German Laser Academy together with Chinese Universities and in Moscow the LZH is establishing a testing, consulting and training centre for laser technology, called the Moscow Laser Innovation Centre. Both projects are set up in close cooperation with the German Laser Industry and cooperation partner in China and Russia. The two projects are presented in this paper.

\section{Sino German Laser Academy}

The Chinese economy has been on a rapid growth course for years. For Germany China is now the most important cooperation partner in Asia. Especially the large German industry sectors, e.g. the automotive manufacturers, profit from this development to a high extent. The production in China secures competitive advantages and a direct entrance for these enterprises to the gigantic Chinese market. But sustainable growth isn't possible in these sectors without qualified engineers and skilled workers.

When it comes to the opening up of new markets, the German machinery- and automobile manufacturers often take over a pioneering role. For more than 15 years Volkswagen/Audi have been active in its Shanghai and Changchun joint ventures. Many suppliers have followed the large automobile groups to China. Since the WTO joining of China which led to a reduction in the import customs duties on automobiles the automobile producers feel exposed to a strong competition for marks shares, prices and quality. In view of this competition the requirements on efficiency and productivity have increased in China.

\section{Laser technology in production}

Laser technology is already an integral part in many production processes. The Automotive industry for example uses laser welding, laser cutting and marking. The handling of such high technological events presupposes a high degree of know-how of the operating personnel. However, the level of education of most technical qualified employees is comparatively low. One reason is the lacking practice orientation in the education. The majority of skilled workers does not possess profession relevant abilities, method competences and the ability to transfer knowledge into practice. Most technical qualified employees also show considerable deficits in the so-called soft-skills like self-initiative, flexibility or independence, e.g. at the remedying of problems. Therefore mainly semi-skilled staff or engineers operate complex laser-machines in China. Moreover, Chinese employees frequently show fear of changing parameters arbitrary since they fear to be dragged to account for possible disturbances.

For German manufacturers in China, the lack of availability of well-trained and qualified employees is a considerable problem and slows down the establishing and development of new and existing manufacturing plants in China. A skilled worker compared to German educational standards is unknown in China; the education of engineers and other technical qualified employees in China has strong theoretical emphases with only low practice orientation and is often not state of the art.

The Laser Zentrum Hannover e.V. (LZH) takes this in consideration and supports German and Chinese companies by training skilled workers and laser operators in China. For more than 12 year the LZH has been training skilled workers and engineers in applied laser technology in Germany. In the context of the laser expert training the participants gain the theoretical and practical knowledge of the four modules, laser basics, laser welding, laser cutting as well as surface processing and treatment. These curricula and course materials serve as a basis for the skilled worker education in China. Sponsored by the Federal Ministry for education and research (BMBF) and supported by enterprises of the German photonics industry the LZH offers at two locations in Shanghai and Changchun the certified laser expert qualification in addition to a wide spectrum of seminars, like laser and work safety, laser in production or robotics. 


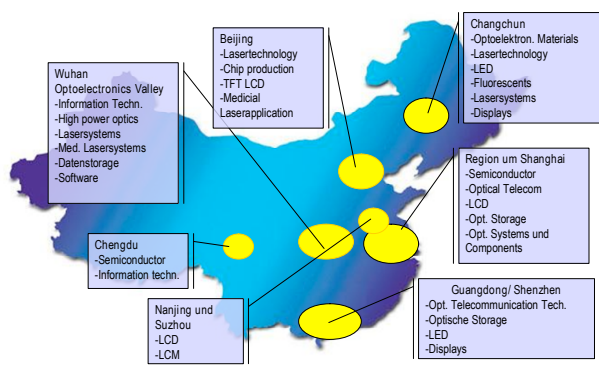

Fig. 1: Important locations for Optical Technologies and applications in China.

As cooperation partners the Changchun University of Science and Technology (CUST) as well as the Tongji University in Shanghai could be won. Both institutions support the project with laboratory space, seminar rooms and training personnel. The central component of the project contains the construction and operation of a nationwide German Chinese Training and Education Centre for laser technology in China, the Sino German Laser Academy. The project pursues the aim of strengthening the technological use of laser technology in German enterprises, German Chinese joint ventures and Chinese enterprises in China by educating a sufficient number of well trained skilled workers and engineers

Besides the theoretical training of state-of-the-art laser technology the practical training is of central importance. Companies of the German photonic industry provide laser-systems and components for the training. The customization of the Curricula and teaching material to cultural and language requirements is imperative for the success of this education-project in China. Together with the LZH the universities develop courses and seminars to establish education in accordance with the quality requirements of the laser technology industry in China. The German companies involved, also offer workshops, seminars and industry days at the two locations.

\section{Moscow Laser Innovation Centre (MLIC)}

For more than twelve years there has been a close cooperation between German and Russian research-facilities and businesses.

Besides the cooperation in joined R\&D-projects, one of the central topics in the past has been also the qualification of Russian managers in the field of laser-technology. Through dedicated measures, such qualifications could have been build up that are inalienable for international cooperation on the level of general management. Information exchange was another main focus of the bilateral cooperation and led to joined presentations of R\&D results of German and Russian R\&D-institutions at international fairs in Germany.

Germany is the most important trade partner of Russia world-wide (11\% of the Russian foreign trade). More than 1000 agencies of German companies are present in Russia, the majority is located in Moscow and St. Petersburg. The number of German companies in Moscow has increased by about $20 \%$ in the last years.

\section{Laser-technology as a future-technology in Russia}

Today is to be determined that highly qualified graduates are trained in the Russian research-facilities in the field of laser-technology. These graduates however have only a limited knowledge about the application potential and the concrete industrial utilization of laser technology and modern optics. Also the qualification level of skilled workers is fairly weak. In the past executives were primarily trained. As a result sensitivity could be implemented in numerous businesses for modern production technologies. Now the aim is to 
train multipliers on the level of skilled workers, technicians and technical decision makers to guarantee a wide circulation of laser knowledge on a long term basis.

\section{Situation of the Russian SMEs}

According to an analysis done by experts of the Laser Association Moscow the momentary use of laser technology does not correspond to the requirements of establishing modern production technologies in Moscow, as the most important industrial center in Russia. Still, the potential of local laser-institutes and companies is scooped out only in bases. The main reasons are:

- insufficient financial resources for investments,

- lacking knowledge of the existing technologies and their use-potential in modern production

- a dramatic lack of qualified skilled workers and technicians that prevent the optimized use of laser-material-processes massively.

\section{Project-description}

The Russian Ministry of Science has decided to construct some regional testing and consulting centers in the last year. Starting in Moscow with the MOSCOW Laser Innovation Centre (MOSLIC). Based on the experiences of the German EBZ (Erprobungs- und Beratungszentren - Testing and Consulting centers) sponsored by the German BMBF in the past, Russian officials rapidly started a knowledge and experience exchange with the former secretariat of the EBZ, the Laser Centre Hanover e.V. to develop a successful concept how to set up a similar structure in Russia.

For the Russian administration, the network of the planned regional EBZ with international partners has top priority, the cooperation with German facilities is most important. On the basis of the industrial and university infrastructure as well as the presence of German businesses, the testing- an consulting center planned for Moscow and later on a second one intended for St. Petersburg have an enormous impact. To be present in Moscow means to have a permanent exchange with the most important Russian companies and researchfacilities.

\section{Choosing the right location: Moscow}

Moscow plays a key-role in the economy of the country. Its share at the Russian GDP amounts to 12.5 percent.

Institutions relevant for the project in Moscow:

Industry:

- 1300 large-scale enterprises with production-places

- Several hundred SMEs with own production

- Job-shops with need of laser technology, laser-material-processing (Approx. 350 businesses are known)

- Approximately 26 manufacturers of laser systems and components (p.a. output approximately 200 systems)

- Several hundred research-institutes

- more than 80 colleges, at which 250000 students are educated in 380 different fields,

- 38 medical research-institutes 


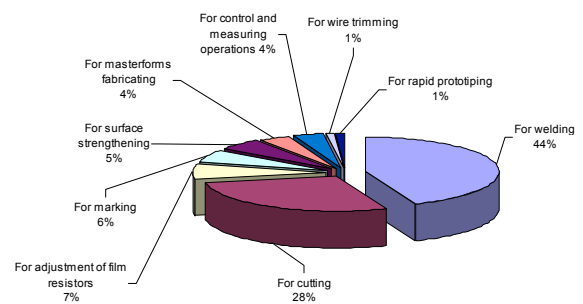

Fig. 2 The structure of industrial laser use in Moscow

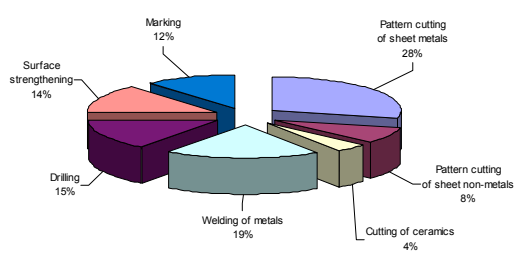

Fig. 3: Structure of demand for mass laser material processing in Moscow

\section{Qualification of personnel:}

The demand of qualified personnel (education in laser-technology) is currently approximately $78 \%$ of the relevant enterprises in the Moscow region.

At the moment none of Moscow's universities is able to guarantee the requested education with modern laser-infrastructure

\section{The role of Laser Centre Hanover e.V.}

The Laser Centre Hanover e.V. has a long experience in organizing and operating laser testing- and consulting centers in Germany. From 1995 until 2001 LZH acted as the central office for 60 centers in Germany as part of a BMBF project. In Moscow, together with its cooperation partner, the Laser Association of Moscow (LAS), the LZH etabslishes the Moscow Laser Innovation Centre (MOSLIC).

The city council of Moscow supports the project with premises for application, testing and training as well as a showroom for German laser technology. The cooperation with German laser and optical components manufacturers (e.g. Trumpf Laser) as well as German laser research institutions is of high meaning for this project.

In the first phase LZH supports LAS by establishing a training and further education infrastructure. Similar to the project in China, the existing training material for the German certified laser expert will be the basis in Moscow, too. Training will be given on one hand to Russian skilled workers, technicians and laser operating personal. On the other hand, manager and engineers of Russian SMEs will be introduced to or trained in modern laser technology for production processes. Courses and seminars will also cover exchange visits in Germany. Besides the training aspect the Innovation Centre will support the Moscow SMEs regarding technological and economic advice for using laser technology and will be able to demonstrate real life material processing methods on modern laser hardware.

\section{Conclusions}

The Chinese economy has been on a rapid growth course for years. For Germany China is now the most important cooperation partner in Asia. Especially the large German industry sectors, e.g. the automotive manufacturers, profit from this development to a high extent. The production in China secures competitive advantages and a direct entrance for these enterprises to the gigantic Chinese market. But sustainable growth is not possible in these sectors without qualified engineers and skilled workers. The Laser Zentrum Hannover e.V. establishes an optimized laser education infrastructure for Chinese personnel secures job and supports German-Chinese joint venture companies by offering education in applied laser technology.

In Moscow the Moscow Laser Innovation Centre offers German companies and research institutes the opportunity to run technology and innovation transfer in Russia by optimizing 
the education infrastructure as well as promoting the use of modern laser material processing systems in Russian SMEs.

Nevertheless both projects are aimed at establishing international network structures for institutions in laser and optical technologies. Especially the testing- and consulting centers offer a chance for an intense long-term relationship between German and Russian SMEs.

\section{Acknowledgements}

The two projects have been financed by the German Federal Ministry of Education and Research (BMBF); FKZ: 13N8575 